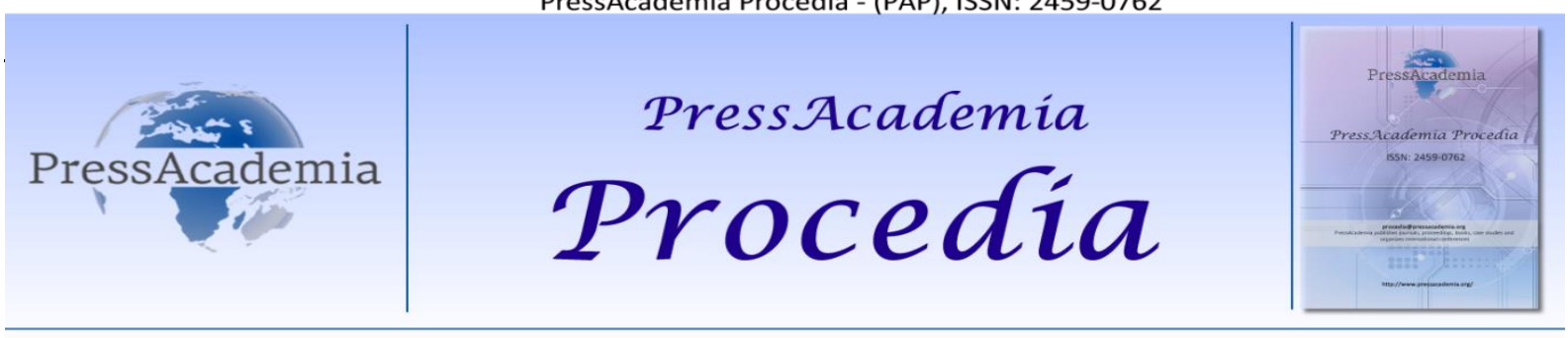

Global Business Research Congress (GBRC), May 24-25, 2017, Istanbul, Turkey.

\title{
ANALYSIS OF FRAGILITY LEVELS OF FRAGILE FIVE IN TERMS OF EXCHANGE RATES
}

\author{
DOI: 10.17261/Pressacademia.2017.409 \\ PAP-GBRC-V.3-2017(24)-p.241-245
}

\section{Halil Simdi ${ }^{1}$, Ayberk Seker ${ }^{2}$}

${ }^{1}$ Sakarya University, Esentepe Campus Sakarya Business School International Trade Department, Sakarya, Turkey. hsimdi@sakarya.edu.tr

${ }^{2}$ Yalova University, Central Campus International Trade and Finance Department, Yalova, Turkey. ayberkseker@yalova.edu.tr

To cite this document

Simdi, H. and A. Seker,(2017). Analysis of fragility level of fragile five in terms of exchange rates.PressAcademia Procedia (PAP), V.3, p.241245.

Permemant link to this document: $\mathrm{http}: / /$ doi.org/10.17261/Pressacademia.2017.409

Copyright: Published by PressAcademia and limited licenced re-use rights only.

\begin{abstract}
This paper analyzes the structural breaks and times of "Fragile Five" currencies' against USD Dollar. Thus study tries to find the consistency of "Fragile Five" via structural break unit root test over currencies. Paper analyzes the structural breaks under two parts which contain Jan 2010- June 2013 and July 2013-Dec 2016 by taking weekly closing currency figures. Study focuses on the fragility of currencies of that countries through Kapetanios unit root test that allows five breaks of series. According to test results all countries except Turkey have one structural break whereas Turkey has four between 2010:01-2013:07. Additionally, between 2013:08-2016:12 all countries have just one structural break date. Findings of the study reveals that classification of "Fragile Five" can be changed after analyze of other macroeconomic indicators in terms of consistency.
\end{abstract}

Keywords: Fragile five, developing countries, exchange rates, 2008 financial Ccisis, kapetanios unit root test. JEL Codes: F31, F40, F41.

\section{DÖVIZ KURU AÇISINDAN KIRILGAN BEŞLININ KIRILGANLIK DERECELERININ ANALIZi}

\section{ÖZET}

Çalışmanın amacı gelişmekte olan kırılgan ülkelerin hangi dönemlerde USD karşısında kırılma yaşadıkları ve bunun kaç defa tekrar ettiğinin bulunmasıdır. Böylelikle Morgan Stanley tarafından açıklanan gruplandırmanın ne derece gerçekçi ve bu ülkelerin kendi içerisinde kırılganlık derecelerinin ne kadar olduğu sonucuna ulaşılmak istenmektedir. Çalışma kapsamında "Kırılgan Beşli” tabirinin ortaya çıkmadan önceki dönem (Ocak 2010 - Temmuz 2013) ile Ağustos 2013 sonrasındaki dönem (Ağustos 2013-Aralık 2016) haftalık kapanış kurları ele alınarak ülkeler arasında karşılaştırma yapılmıştır. Çalışmada beş kırılmaya kadar izin veren Kapetanios birim kök testi kullanılarak ülkelerin dolar karşısında para birimlerinin ne kadar kırılgan oldukları ortaya koyulmaya çalışılmıştır. Test sonuçlarına göre 2010:01:01-2013:07:31 döneminde Türkiye dışındaki ülkelerde tek kırılma gözlemlenirken Türkiye'de bu dönem için kırılma sayısı dört olarak gerçekleşmiştir. İkinci dönemde ise tüm ülkelerin tek kırılma yaşadıkları testin sonucu olarak bulunmuştur. Çalışmanın sonucunda "Kırılgan Beşli" gruplandırılmasının yeniden değerlendirilip beş ülkenin diğer makroekonomik göstergelerindeki kırılma tarihlerine de bakılması gruplandırma açısından daha tutarlı sonuçlar verebilir.

Anahtar Kelimeler: Kırılgan Beşli, Gelişmekte Olan Ülkeler, Döviz Kurları, 2008 Finansal Krizi, Kapetanios Birim Kök Testi. JEL Kodları: F31, F40, F41. 


\section{GíRiş}

Uluslararası ekonomide küreselleşme ile birlikte ülkelerin birbirleriyle olan ekonomik ilişkileri giderek artmıştır. Artan bu ekonomik ilişkiler ülkelerin ekonomilerini birbirlerine karşı daha duyarlı ve daha kııılgan bir yapıya dönüştürmüştür. 2013 yılının Mayıs ayında Amerikan Merkez Bankası'nın (FED) tahvil alımlarına kısıtlama getireceğini duyurması ve ABD'nin para politikasını sıkılaştırması ile birlikte, uluslararası sermaye piyasaları hareketlenmiş ve ülkelerden ani fon çıkışları gerçekleşmiştir. Yaşanan ani fon çıkışları en çok, ihtiyaç duydukları fonları kısa süreli yabancı sermayeler ile sağlayan ve cari açıklarını bu şekilde finanse etmeye çalışan gelişmekte olan ülkeleri etkilemiştir.

2013 yılının Ağustos ayında Morgan Stanley tarafından açıklanan raporda, ABD Doları karşısında en fazla değer kaybeden beş gelişmekte olan ülke -Brezilya, Endonezya, Güney Afrika, Hindistan ve Türkiye- olarak belirlenmiş ve bu ülkelere "Kırılgan Beşli" tanımlaması yapılmışırı. Rapora göre, "Kırılgan Beşli" ülkelerinin yüksek cari açıklara sahip oldukları ve dolayısıyla bu durumun "Kırılgan Beşli" ülkelerini yabancı sermaye akımlarına daha bağımlı hale getirdiği belirtilmiştir. Cari açıklarının, ülkelerin gelirlerinin \% 5'inden daha yüksek seviyelere çıktığı ortaya koyulmuştur (Morgan Stanley, 2013b). Bu doğrultuda "Kırılgan Beşli" ülkeleri; yüksek cari açık, enflasyon, döviz kurlarına ve zayıf ekonomik büyüme oranlarına sahip ve dış ekonomik koşullara karşı savunmasız olarak nitelendirilmiştir (Morgan Stanley, 2013a).

Amerikan Merkez Bankası'nın (FED) 2013 raporu sonrasında "Kırılgan Beşli" ülkelerinin yüksek cari açık oranları, enflasyon riskleri, düşük ekonomik büyüme oranları ve kısa süreli yabancı sermayeye bağlı ekonomik yapılarına bağlı olarak döviz kuru riski ortaya çıkmaktadır. Bu doğrultuda çalışmanın amacı; Ocak 2010 - Aralık 2016 tarihleri arasındaki haftalık verileri kullanarak, gelişmekte olan kırılgan ülkelerin hangi dönemlerde Amerikan Doları (USD) karşısında kırılma yaşadıkları ve bunun kaç defa tekrar ettiğinin ortaya çıkarılmasıdır. Böylelikle Morgan Stanley tarafından açıklanan "Kırılgan Beşli" gruplandırmasının ne derece gerçekçi ve bu ülkelerin kendi içerisinde kırılganlık derecelerinin ne kadar olduğu sonucuna ulaşılmak istenmektedir. Bu doğrultuda ikinci bölümde; döviz kurlarının değişimlerini açıklamaya yönelik teoriler açıklanmıştır. Üçüncü bölümde ise, çalışma ile ilgili literatür taraması gerçekleştirilmiştir. Dördüncü bölümde, ekonometrik yöntemler vasıtasıyla çalışmaya ilişkin analizler gerçekleştirilmiş, ardından sonuç ve değerlendirmeler ile çalışma tamamlanmıştır.

\section{LiTERATÜR INCELEMESI}

Kur değişimlerini geleneksel olarak inceleyen teoriler genellikle ticaret akımlarına dayanan ve uzun dönemdeki denge değerlerini tahmin etmeye çalışmaktadır. 20. yüzyılın ikinci yarısında döviz kurlarını açıklamak için ortaya koyulan teoriler ise döviz kuru değişimlerini finansal bir olay olarak ele alıp ani ve aşırı değişimleri açıklamaya çalışmaktadır (Seyidoğlu, 2013: 437).

Döviz kuru değişimlerini açıklamaya yönelik geleneksel teoriler; dış ticaret akımları yaklaşımı ve satın alma gücü paritesi yaklaşımı olarak karşımıza çıkmaktadır. Modern teoriler ise; parasal (monetarist) yaklaşım ve portfolyo yaklaşımı olarak ortaya koyulmaktadır.

Dış Ticaret Akımları Yaklaşımı, bir ülkenin parasının değerini belirleyen etkenin o ülkenin mal ihracat ve ithalâtı olduğunu ileri sürmektedir. Ülkenin ihracatın ithalâtından büyük olması (dış ticaret bilançosunun fazla vermesi) halinde ulusal paranın dış değerinin yükseleceğini belirtmektedir. Bu durumun aksi halinde, yani ithalâtın ihracatı aşması durumunda da ulusal paranın değer yitireceğini ortaya koymaktadır (Öztürk ve Bayraktar, 2010: 160).

Geleneksel teoriler arasında yer alan Satın Alma Gücü Paritesi Yaklaşımı, tek fiyat kanununa dayanarak döviz kuru değişimlerine açıklık getirmeye çalışmaktadır. Satın alma gücü paritesi yaklaşımına göre, döviz kurlarındaki büyük değişimler ülkelerin enflasyon oranları ile ilişkilidir (Özkan, 2011: 186). Başka bir ifade ile döviz kurları ülkelerin iç ve dış fiyat endeksleri oranlarının farklarıyla yaklaşık olarak aynıdır (Stockman, 1980: 675).

Modern yaklaşımlardan biri olan Parasalı Yaklaşım’a göre, ulusal paraların fiyatı olan döviz kurları ilgili paraların arz ve talebine göre oluşmaktadır. Talep edilen para miktarı arz edilen para miktarından yüksek olursa, ilgili para birimi döviz piyasasında değer kazanmaktadır. Arz miktarının talep edilen miktarı aşması halinde ise ilgili para döviz piyasasında değer kaybetmektedir (Seyidoğlu, 2013: 446). Bu doğrultuda, ulusal para arzının yabancı para arzına göre daha fazla artması halinde döviz kurlarının da bu oranda yükselmesi beklenmektedir (Öztürk ve Bayraktar, 2010: 169).

Modern yaklaşımlardan bir diğeri ise Portfolyo Dengesi Yaklaşımı'dır. Bu yaklaşıma göre, döviz kurlarında meydana gelen kısa dönemli dalgalanmalar, yabancı menkul değerleri arz ve talebindeki değişmeler ile açıklanmaktadır (Seyidoğlu, 2013: 450). Parasalcı yaklaşımda yerli menkuller ile yabancı menkullerin birbirlerini tam ikame ettiği ve risklerinin aynı olduğu varsayılırken, portfolyo dengesi yaklaşımında yatırımcılar belirli bir risk düzeyinde en yüksek getiriyi elde edecek şekilde portföylerini oluşturmaktadırlar (Öztürk ve Bayraktar, 2010: 171). 
Literatürde Kırılgan Beşli ülkelerinin finansal kırılganlıkları, döviz krizleri ve makroekonomik göstergeleri ile ilgili çeşitli çalışmalar bulunmakla birlikte, Morgan Stanley'in 2013 raporu öncesi ve sonrası ile ilgili kıyaslama gerçekleştiren bir çalışmaya rastlanılmamıştır.

Eichengreen ve Hausmann (1999) döviz kurları ve finansal kırılganlık ile ilgili üç önemli görüşü analiz etmişlerdir. Çalışmanın sonucunda, döviz kurları ve finansal kırılganlığa çözüm olarak dolarizasyonu ve piyasa koşullarını daha iyi hale getirerek pazardaki manüpilasyonların önlenmesi gerektiğini ortaya koymuşlardır.

Özkan (2005) Türkiye'nin yaşadığı döviz ve finansal krizlerin nedenlerini araştırmak üzere reel ekonomi, kamu maliyesi ve finansal sektördeki gelişmeleri değerlendirmiştir. Çalışmada Türkiye'nin ekonomik sorunlarının ve ekonomik zayıflarının nedenleri; yüksek borç düzeyi nedeniyle oluşan zayıf dış pozisyon, iç borçlanma faiz ödemelerinin rekor düzeylerde yüksek olması dolayısıyla oluşan zayıf mali pozisyon ve finansal ve bankacılık sektörlerindeki zayıflıklar olarak belirtilmiştir.

Ünver ve Doğru (2015), kırılgan beşli ülkelerin uzun dönemli finansal sürdürülebilirlik ve kredi notları bakımından kırılganlığın belirleyicilerini analiz etmişlerdir. Çalışma sonucunda; finansal sürdürülebilirlik ile cari işlemler dengesi, gayrisafi yurt içi hasıla, toplam rezervler, enerji ithalatı, kurlar, dış borç ve özel sektör borcu arasında istatistiksel olarak anlamlı ilişkilerin bulunduğu tespit edilmiştir.

Küçüksille ve Karaoğlan (2016) çalışmalarında kırılgan beşli ülkelerinin para birimlerinin Amerikan Doları (USD) karşıSındaki getirilerinin birbirleri arasındaki ilişkileri ortaya koymuştur. Çalışma sonucunda; Amerikan Doları/Türk Lirası paritesinin getirisini en fazla etkileyen parite getirileri sırasıyla Amerikan Doları/Güney Afrika Randı, Amerikan Doları/Hindistan Rupisi ve Amerikan Doları/Brezilya Reali olurken, Amerikan Doları/ Hindistan Rupisi paritesinin getirisini en fazla etkileyen parite getirileri ise Amerikan Doları/Endonezya Rupiahı, Amerikan Doları/Türk Lirası ve Amerikan Doları/Brezilya Reali olduğu tespit edilmiştir.

Ümit (2016) kırılgan beşli ülkelerinin reel döviz kurlarının durağanlığını geleneksel ve yapısal kırılmalı birim kök testleri ile sınamıştır. Geleneksel birim kök testi sonuçlarına göre kırılgan beşli ülkelerinde satın alma gücü paritesi hipotezinin geçerli olmadığı ortaya koyulmuştur. Satın alma gücü paritesi hipotezinin, Zivot-Andrews tek yapısal kırılmalı birim kök testi sonuçlarına göre Brezilya ve Hindistan'da, Lee-Strazicich iki yapısal kırılmalı test sonuçlarına göre ise yalnızca Hindistan'da, Carrion-i-Silvestre beş yapısal kırılmalı test sonuçlarına göre ise Güney Afrika ve Hindistan'da geçerli olduğu tespit edilmiştir.

\section{VERI VE YÖNTEM}

Çalışmada “Kırılgan Beşli" ülkelerinin Ocak 2010:Aralık 2016 dönemindeki haftalık kapanış kurlarının doğal logaritmik veri setleri kullanılmıştır. Illgili veri setleri ülkelerin merkez bankalarından elde edilmiştir. Ülkelerin döviz kuru açısından kırılganlıklarının kırılmalı birim kök testi yardımıyla ortaya koyulup ülkelerin kırılganlık dereceleri ortaya koyulmaya çalışılacaktır. Geleneksel birim kök testlerinden ADF testi, eşitlik (1)'de verilen regresyon modelinin en küçük kareler (EKK) tahmin edicisi ile tahin edilen $\beta_{2}$ parametresine karşılık gelen tistatistiğe dayanmaktadır (aşağıdaki eşitlikte var olan $t$ modelin trendli tahmin edildiğini göstermektedir):

$$
\Delta \mathrm{y}_{\mathrm{t}}=\beta_{0}+\beta_{1} \mathrm{y}_{\mathrm{t}-1}+\sum_{i=1}^{k} \gamma_{\mathrm{i}} \Delta \mathrm{y}_{\mathrm{t}-\mathrm{i}}+\varepsilon_{\mathrm{t}}, \mathrm{t}=1, \ldots, \mathrm{T}
$$

ADF birim kök testi kısaca $\mathrm{H}_{0}: \beta_{1}=0$ hipotezi tek yönlü alternatif hipotez olan $\mathrm{H}_{1}: \beta_{2}<0$ 'a karşı test edilir. Eşitlik (1) de eşitliğin sağında $\Delta y \mathrm{t}$ bağımlı değişkenin gecikmelerinin eklenmesi regresyon modelindeki hata serisini otokorelasyonsuz hale getirmek için yapılan parametrik bir ayarlamadır.

Standart birim kök testi yerine elimizdeki verilerde herhangi bir kırılma olup olmadığını teyit etmek adına George Kapetanios (2005) tarafından geliştirilen ve 5 kırılmaya kadar izin veren birim kök testi çalışmamızda kullanılmıştır. Kapetanios birim kök testi, Zivot ve Andrews ile Lumsdaine ve Papell kırılmalı birim kök testlerinin geliştirilmiş hali olarak nitelendirilebilir. Kapetanios birim kök testinin denklemi ise aşağıda verilmiştir:

$$
\mathrm{Y}_{\mathrm{t}}=\mu_{0}+\mu_{1 \mathrm{t}}+\alpha \mathrm{y}_{\mathrm{t}-1}+\sum_{i=1}^{k} \gamma_{\mathrm{i}} \Delta y_{\mathrm{t}-\mathrm{i}}+\sum_{i=1}^{m} \phi \mathrm{DU}_{\mathrm{i}, \mathrm{t}}+\sum_{i=1}^{m} \psi \mathrm{DT}_{\mathrm{i}, \mathrm{t}}+\varepsilon_{\mathrm{t}}
$$

Kukla değişkenler $\mathrm{DU}_{i, t}=1\left(\mathrm{t}>\mathrm{T}_{\mathrm{b}, \mathrm{i}}\right)$ ve $\mathrm{DT}_{\mathrm{i}, \mathrm{t}}=1\left(\mathrm{t}>\mathrm{T}_{\mathrm{b}, \mathrm{i}}\right)\left(\mathrm{t}-\mathrm{T}_{\mathrm{b}, \mathrm{i}}\right)$ sırasıyla ortalama ve trent için yapısal kırılmaları vermektedir. Aynı zamanda $T_{b, i}$ yapısal kırılmanın ne zaman gerçekleştiğini göstermektedir. Kapetanios birim kök testinin boş hipotezi $H_{0}$ : $\rho=1, \mu_{1}=\varphi_{1}=\varphi_{1}=\ldots .=\varphi_{\text {smax }}=\psi_{1}=\psi_{2}=\ldots .=\psi_{\text {smax }}=0$. Analiz sonucunda elde edilecek olan en küçük $\mathrm{t}$ istatistiği tüm $\rho$ 'ler için m kırılmaya kadar en küçük kareler yönteminden elde edilen kalıntıları minimize etmektedir (Kapetanios, 2005: 124). Hesaplanan test istatistiği kırılma sayılarına göre verilen kritik değer daha büyükse serinin birim köklü olduğunu gösteren temel hipotez ret edilerek serinin durağan olduğu sonucuna ulaşılır.

\section{BULGULAR VE TARTIŞMA}


Çalışmada ilgili serilerin durağanlığı yapısal kırılmaları dikkate almayan ADF birim kök testi yardımıyla hesaplanmıştır. Buna ek olarak çalışmanın amacına uygun olarak ülke gruplarının döviz kurlarına ilişkin kırılganlıklarını görmek adına yapısal kırılmalara izin veren Kapetanios birim kök testi analizi yapılmıştır.

Tablo 1'de serilerin ADF testine göre birim kök analizi sonuçları bulunmaktadır.

Tablo 1: ADF Birim Kök Test Sonuçları

\begin{tabular}{|c|c|c|c|c|c|c|}
\hline & \multicolumn{2}{|c|}{ I(0) } & \multicolumn{2}{c|}{ I(0)+Trend } & \multicolumn{2}{c|}{ I(1)+Trend } \\
\hline Değişkenler & t-istatistiği & Olasılık Değeri & t-istatistiği & Olasılık Değeri & t-istatistiği & Olasılık Değeri \\
\hline Brezilya-1 & $-0,441$ & 0,898 & $-1,723$ & 0,737 & $-14,889$ & $0,000^{* * *}$ \\
\hline Brezilya-2 & $-1,054$ & 0,733 & $-0,809$ & 0,962 & $-11,994$ & $0,000^{* * *}$ \\
\hline Endonezya-1 & 0,6219 & 0,99 & $-0,889$ & 0,954 & $-15,623$ & $0,000^{* * *}$ \\
\hline Endonezya-2 & $-2,813$ & $0,058^{*}$ & $-2,62$ & 0,271 & $-12,03$ & $0,000^{* * *}$ \\
\hline Hindistan-1 & $-0,0086$ & 0,955 & $-1,98$ & 0,607 & $-11,84$ & $0,000^{* * *}$ \\
\hline Hindistan-2 & $-1,213$ & 0,668 & $-2,507$ & 0,324 & $-9,924$ & $0,000^{* * *}$ \\
\hline Güney Afrika-1 & $-0,332$ & 0,916 & $-2,439$ & 0,358 & $-16,202$ & $0,000^{* * *}$ \\
\hline Güney Afrika-2 & $-1,316$ & 0,621 & $-1,788$ & 0,706 & $-13,983$ & $0,000^{* * *}$ \\
\hline Türkiye-1 & $-0,96$ & 0,766 & $-2,015$ & 0,588 & $-13,096$ & $0,000^{* * *}$ \\
\hline Türkiye-2 & $-0,121$ & 0,944 & $-2,107$ & 0,537 & $-12,668$ & $0,000^{* * *}$ \\
\hline
\end{tabular}

Kaynak: Yazarların hesaplamaları.

Not: Ülkeler alfabetik olarak sıralanmıştır. Ülkelerin yanında bulunan sayılar birinci ve ikinci dönemi nitelendirmektedir.*,** ve*** sırasıyla \%10, \%5 ve $\% 1$ seviyesinde anlamlılığı ifade etmektedir.

Geleneksel birim kök testi sonuçlarına göre yalnızca Endonezya'nın seviyesinde \%10 anlamlılık derecesinde durağan olduğu gözlemlenmiştir. Ancak seriye trend eklendiği zaman veri setinin diğer ülkeler gibi durağan olmadığı sonucuna ulaşılmıştır. Diğer taraftan tüm veri setinin birinci farklarında serilerin durağan oldukları ADF birim kök testine göre elde edilmiştir. Tablo 2 'de ise yapısal kırılmalara izin veren Kapetanios testinin sonuçları görülebilir.

Tablo 2: Kırılgan Beşlinin Kapetanios Birim Kök Testi Sonuçları

\begin{tabular}{|c|c|c|c|}
\hline \multicolumn{4}{|c|}{ Ocak 2010 - Haziran 2013 Dönemi } \\
\hline Değişkenler & t-istatistiği & Kırılma Sayısı & Kırılma Tarihleri \\
\hline Brezilya-1 & 4,39 & 1 & 02.09 .2011 \\
\hline Endonezya-1 & 4,765 & 1 & 28.05 .2010 \\
\hline Hindistan-1 & 4,31 & 1 & 02.09 .2011 \\
\hline Güney Afrika-1 & $5,046^{*}$ & 1 & 21.05 .2010 \\
\hline Türkiye-1 & 3,562 & 4 & $14.05 .2010 ; 05.11 .2010 ; 10.06 .2011 ; 30.12 .2011$ \\
\hline & & Temmuz 2013 - Aralık 2016 Dönemi \\
\hline Değişkenler & t-istatistiği & Kırılma Sayısı & Kırılma Tarihleri \\
\hline Brezilya-2 & 3,301 & 1 & 31.01 .2014 \\
\hline Endonezya-2 & 3,965 & 1 & 29.11 .2013 \\
\hline Hindistan-2 & $6,00 * * *$ & 1 & 31.01 .2014 \\
\hline Güney Afrika-2 & 4,468 & 1 & 16.10 .2015 \\
\hline Türkiye-2 & 3,272 & 1 & 24.01 .2014 \\
\hline
\end{tabular}

Not: Ülkeler alfabetik olarak sıralanmıştır. Ülkelerin yanında bulunan sayılar birinci ve ikinci dönemi nitelendirmektedir.*,** ve*** sırasıyla \%10, \%5 ve $\% 1$ seviyesinde anlamlıı̆̆ı ifade etmektedir. 
Kapetanios (2005) yapısal kırılmalı birim kök testi sonuçlarına göre 2010:01:01-2013:12:31 döneminde Türkiye dışındaki ülkelerde tek kırılma gözlemlenirken Türkiye'de bu dönem için kırılma sayısı dört olarak gerçekleşmiştir. Buna ek olarak ikinci dönemde tüm ülkelerin tek kırılma yaşadıkları testin sonucu olarak bulunmuştur. Kırılma tarihleri açısından birinci dönemde Güney Afrika'nın kırılmasıyla beraber birim kök testi istatistiksel açıdan \%10 seviyesinde anlamlı iken ikinci dönemde ise yalnızca Hindistan'ın kırılması \%1 seviyesinde anlamlıdır. Sonuç olarak Türkiye 2010-2013 döneminde diğer dört ülkeden fazla sayıda kırılma yaşamıştır ve bu dönemde Hindistan haricinde diğer ülkeler Mayıs 2010 döneminde kırılma yaşamışlardır.

\section{SONUÇ}

Çalışmamızda incelenen "Kırılgan Beşli” döviz piyasalarının farklı dönemlerde kırıldıkları görülmüştür. Morgan Stanley'in yapmış olduğu gruplandırmadaki ülkeler arasındaki en kırılgan ülkenin döviz kuru açısından Türkiye olduğu söylenebilir. Türkiye dışındaki ülkelerin tek kırılma yaşadıkları dönemde Türkiye dört kırılma yaşamıştır. Buna ek olarak ülkelerin de kendi içlerinde kırılma tarihleri açısından ayrıştığı vurgulanabilir. Brezilya ve Hindistan'ın her iki dönemde de kırılma tarihleri aynı gerçekleşmişken birinci dönemde Endonezya, Güney Afrika ve Türkiye'nin (ilk kırılma tarihi) de hemen hemen aynı haftalarda kırılma yaşadıkları görülmektedir. Ayrıca Türkiye, Brezilya ve Hindistan ikilisinin kırılma tarihlerinden üç ay önce ve üç ay sonra iki kırılma dönemi yaşamıştır.

İkinci dönemde yani "Kırılgan Beşli" tabirinin ortaya atılmasından sonra Güney Afrika dışındaki ülkelerin üç aylık dönem içerisinde döviz kurlarında kırılma yaşadıkları sonucuna ulaşılmıştır. Ağustos 2013 - Aralık 2016 döneminde "Kırılgan Beşli" Amerikan Doları kuru açısından ilk döneme nazaran birbirlerine daha fazla benzemeye başladıkları belirtilebilir.

Çalışmamızın amacı, "Kırılgan Beşli" içerisinde döviz kuru açısından ülkelerin kırılganlık derecelerinin ortaya koyulmasıdır. Bu sebepten dolayı daha kırılgan olduğu gözlenen Türkiye'nin kırılganlık gösterdiği ilk dönemde Avrupa borç krizinden diğer ülkelere nazaran daha fazla etkilendiği vurgulanabilir. Gerek $A B^{\prime}$ ye aday ülke statüsünde olması ve karşlıklı ticari işbirlikleri gerekse coğrafi yakınlık Türkiye'nin Avrupa'da yaşanan ya da yaşanacak krizlerden gruptaki diğer ülkelere göre daha fazla olumsuz şekilde etkilenmesinin nedenleri arasında gösterilebilir. Bununla beraber Türkiye'nin Avrupa'da yaşanacak herhangi olumlu bir ekonomik gelişmeye tepkisinin daha fazla olacağı sonucuna da ulaşılabilir.

"Kırılgan Beşli" ye ilişkin olarak yapılacak yeni çalışmalarda ülkelerin diğer makroekonomik değişkenlere göre yine kırıganlıklarının test edilebilmesiyle beraber eşbütünleşme testleri ile de ilgili ülkelerin beraber hareket edip etmedikleri sınanabilir.

\section{KAYNAKLAR}

Eichengreen, B., Hausmann, R. (1999). Exchange rates and financial fragility. NBER Working Paper Series Cambridge, Working Paper 7418.

Kapetanios, G. (2005). Unit root testing against the alternative hypothesis of up to m structural breaks. Journal of Time Series Analysis, vol. 26 , no. 1 , p. $123-133$

Küçüksille, E., Karaoğlan, S. (2016). Kırılgan beşli ülkelerin amerikan doları bazında parite getirileri arasındaki ilişkilerin analizi. Sosyal Bilimler Dergisi, ICEBSS Özel Sayısı. p. 46-61.

Morgan Stanley. (2013a). Currencies FX Pulse. Morgan Stanley Research. 1 August 2013

Morgan Stanley. (2013b). Tales from the Emerging World. Investment Management. 3 December 2013.

Özkan, F. G. (2005). Currency and financial crises in turkey 2000-2001: bad fundamentals or bad luck? World Economy, vol. 28, no. 4, p. 541-572.

Öztürk, N., Bayraktar, Y. (2010). Döviz kurlarını açıklamaya yönelik yeni yaklaşımlar. Cumhuriyet Üniversitesi İktisadi ve İdari Bilimler Dergisi, vol. 11, no. 1, p. 157-191.

Seyidoğlu, H. (2013). Uluslararası iktisat: teori, politika ve uygulama. İstanbul: Güzem Can Yayınları.

Stockman, A. C. (1980). A theory of exchange rate determination. Journal of Political Economy, Vol. 88, No. 4, p. 673-698.

Ümit, Ö. (2016). Stationarity of real exchange rates in the "fragile five": analysis with structural breaks. International Journal of Economics and Finance, Vol. 8, No. 4, p. 254-270.

Ünver, M., Doğru, B. (2015). The determinants of economic fragility: case of the fragile five countries. Akdeniz iiBF Dergisi, Vol. 31 , p. 1- 24. 